\title{
Consideraciones políticas sobre el plan económico del gobierno
}

Este comentario contiene cuatro puntos principales. En primer lugar, ubica las medidas económicas, anunciadas el 2 de febrero por el presidente Calderón Sol (El Diario de Hoy, 3 febrero de 1995, pp. 22-23), en la actual coyuntura política y económica. En segundo lugar, trata de descifrar el sentido de estas medidas desde la perspectiva del actual Ministro de Hacienda Manuel Enrique Hinds. En tercer lugar, señala los graves vacíos políticos y económicos de dichas medidas. En cuarto lugar, analiza la consulta hecha sobre las medidas a través del criterio de acceso de los diferentes grupos sociales a la toma de decisiones.

Los acuerdos de paz, en el marco de la transición de la guerra a un proceso de democratización, siguen siendo las coordenadas fundamentales de la coyuntura política. Uno de los logros más importantes que los salvadoreños podemos obtener del cumplimiento cabal de los acuerdos es erradicar como alternativa para el control del Estado a un régimen autoritario-militar que tenga como una de sus funciones principales la protección de los intereses económicos de un pequeño, pero poderoso grupo de salvadoreños.

El área más débil en los acuerdos de paz es el tema económico social. El gobierno logró que el programa de ajuste estructural no fuera sujeto de negociación. El plan de reconstrucción nacional se condicionó al programa de ajuste. El foro para la concertación económico social entre el gobierno, los trabajadores y los empresarios fue boicoteado, principalmente por las gremiales de la gran empresa privada, y actualmente se encuentra sin vida. El programa de transferencia de tierras, crédito, capacitación y la asistencia técnica para los ex combatientes se encuentra con serios retrasos que están causando inestabilidad política.

A tres años de la firma de los acuerdos, no cabe duda que la etapa de la luna de miel por el fin del conflicto armado ha terminado. La reelección de ARENA en 1994 fue en gran medida fruto de dicha luna de miel. Así lo pone en evidencia la opinión pública cuando se le preguntó sobre el principal logro del gobierno de Cristiani. Los resultados del IUDOP muestran que para el 46.3 por ciento de los salvadoreños fue la consecución de la paz el logro principal; mientras que, sólo para el 4.4 por ciento de salvadoreños fueron las mejoras económicas. El mismo programa de reconstrucción nacional fue utilizado políticamente para favorecer la imagen del partido gobernante. Todo esto ayuda a explicar la abrumadora victoria electoral de ARENA que, a pesar del grave problema de imagen de su candidato presidencial, en la segunda vuelta obtuvo el 68.2 por ciento de los votos válidos.

A partir de junio de 1994, el nivel de popularidad del presidente Calderón Sol se ha erosionado rápidamente. Un indicador de lo anterior nos lo ofrece el IUDOP al pedirle a los salvadoreños que evalúen al presidente de la república usando una escala de cero a diez. A cien días de su gobierno, 
el promedio fue 6, el cual ha descendido a 4.5 para febrero de 1995 . El pueblo percibe claramente este fenómeno. Nuestro pueblo utiliza los chistes, como un medio de expresión de la "sabiduría popular", y uno de ellos dice que el presidente Calderón Sol se parece a algunos televisores coreanos porque pierde la imagen en seis meses.

Otro problema fundamental a nivel político es la poca credibilidad que tienen instituciones claves tales como el sistema judicial y los partidos políticos. En la encuesta de febrero de 1995, el IUDOP preguntó sobre el nivel de confianza de los salvadoreños en los partidos políticos. El resultado fue que el 54 por ciento de los salvadoreños no tienen ninguna confianza en los partidos y el 28 por ciento expresó tener poca confianza en ellos. Estos datos son preocupantes porque significa que los salvadoreños no consideran a los partidos como representantes de sus intereses. Queda el problema de cómo hacer para que los gobernantes escuchen la voz y los intereses de los salvadoreños.

En cuanto a la coyuntura económica, nos parece que uno de los hechos más relevantes a tener presente es que existen dos lecturas, casi opuestas, sobre la situación económica del país. Si la lectura se hace con base a los datos macroeconómicos, como la tasa de crecimiento económico del 5 por ciento, se concluye que la situación es buena. Si la lectura se hace a partir de la experiencia concreta de la mayoría de los salvadoreños para ganarse la vida cotidianamente se concluye que la situación económica está mal. Ambos datos son ciertos y constituyen parte del mosaico de nuestra realidad. La moraleja es que buenas cifras macroeconómicas distan mucho de significar bienestar para las mayorías populares. Por tanto, se debe pensar en medidas concretas para atender no sólo a los problemas macroeconómicos, sino también para satisfacer las necesidades concretas y cotidianas de nuestro pueblo.

$\mathrm{El}$ anuncio de las medidas económicas genera desconcierto dentro de este marco coyuntural político económico. Una de las preguntas que surge sobre estas medidas es su propósito. Para tratar de responder a dicha interrogante nos basaremos en un informe elaborado por el actual Ministro de Hacienda Hinds, en abril de 1993, presentado al

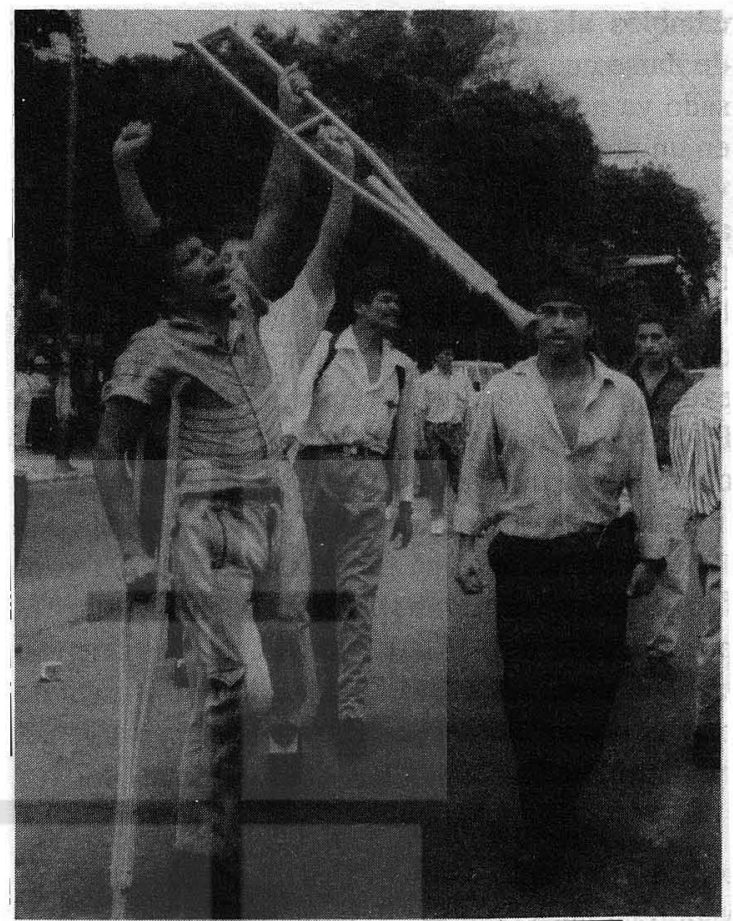

Banco Mundial y titulado "El Salvador: ¿ahora qué?". En síntesis, el informe argumenta lo siguiente. Las medidas de ajuste iniciadas en junio de 1989 fueron correctas. Se buscaba que las exportaciones no tradicionales, sobre todo agrícolas, se constituyeran en el motor del desarrollo. Sin embargo, en 1993, la contribución de la industria y la agricultura en el producto interno bruto ha tendido a declinar; mientras que, la contribución de los servicios ha continuado incrementándose. Se cuestiona si dicha tendencia es sostenible a largo plazo, si la agricultura y la industria no se recuperan y los servicios no se vuelven exportables.

Ante esta situación, el ministro Hinds recomienda medidas complementarias urgentes que tengan como objetivo que El Salvador se integre en la economía internacional. Específicamente, recomienda integrarse a Estados Unidos, teniendo presente que cualquier gran ciudad de este país tiene más poder de compra que el mercado común centroamericano. Señala que un posible nicho es la actividad textilera ya que para Estados Unidos es muy alto el costo de oportunidad de seguir manteniendo protegida a dicha industria. Ahora bien, la implementación de esta estrategia exige 
cambios al empresario salvadoreño, en términos de darse cuenta que los grandes beneficios del pasado ya no se pueden mantener a menos que entre en un proceso de innovación. La forma más efectiva para entrar en ese proceso es abrir las fronteras a la inversión extranjera, cuyo beneficio más importante sería permitir a los empresarios nacionales establecer conexiones de negocios con los mercados internacionales. Sin embargo, la inversión extranjera no vendrá si la infraestructura física de El Salvador no es adecuada para que un negocio opere en los mercados internacionales. Los problemas de infraestructura más graves que señala son las comunicaciones, el suministro de energía y las facilidades de transporte. De ahí que la privatización de ANTEL, de CEL, de los puertos, etc., se presenta como el siguiente paso inmediato para el desarrollo del país, desde la perspectiva del ministro Hinds.

El planteamiento anterior ignora, por una parte, los problemas estructurales de la economía salvadoreña tales como la desarticulación del aparato productivo, la gran concentración de la riqueza, la marginación histórica de los pequeños productores de granos básicos, y en general, el poco desarrollo del mercado interno al cual se encuentra vinculada la mayoría de la población. Por otra parte, es cuestionable pensar que la maquila pueda convertirse en fuente de desarrollo para los salvadoreños. La maquila genera empleo, pero mal remunerado. Muchas veces no cumple con los requisitos del Código de Trabajo. No ofrece una capacitación que cambie cualitativamente la productividad del trabajador. Más aún, la extensión e intensidad de la jornada de trabajo lleva a un desgaste acelerado de la capacidad productiva de los trabajadores. Un punto más en contra de la maquila es su desarticulación con el resto de los sectores de la economía nacional (Ver el artículo del Departamento de Economía, “QQué modelo económico y qué modelo de sociedad queremos?").

Además, tener como centro de la estrategia un proceso de privatización sin reglas claras y concertadas conlleva a un enfrentamiento frontal con los trabajadores. Lo cual significa desestabilización política, causada por el mal manejo de la política económica que está llevando a cabo el go- bierno. A todo lo anterior debemos sumarle el alarmante nivel de criminalidad que estamos sufriendo como pueblo, el problema más importante para los salvadoreños en la actualidad y el "arancel" más alto que tenemos en contra de la inversión extranjera.

Ante esta situación, no es de extrañar que incluso algunas gremiales de la gran empresa privada hayan expresado diferencias y reservas respecto al plan, aunque a nivel de los medios de comunicación expresen su respaldo. Los medianos, los pequeños y los micro empresarios organizados han expresado su oposición. Lo mismo han hecho los obreros, los empleados públicos y los campesinos organizados. Varias universidades y centros de investigación han expresado su oposición al plan. Finalmente, la opinión pública también se ha expresado, según informa el IUDOP, seis de cada diez de los salvadoreños que conocen el plan económico están en contra del mismo.

En cuanto a la forma en que el plan fue consultado tenemos tres críticas principales. Primero, el plan se consultó fundamentalmente con las gremiales de la gran empresa privada. Sin embargo, los representantes de estas gremiales han expresado que no tuvieron a disposición la información necesaria para discutir con mayor profundidad las propuestas y, por lo tanto, la mayor parte de las discusiones se centraron en aspectos puntuales perdiéndose la perspectiva global. Segundo, los empresarios medianos, pequeños y micros, los obreros, los campesinos y los empleados públicos organizados no fueron consultados. Tercero, al pueblo en general se le informó, pero no se le consultó. Cabe destacar que la crisis de confiabilidad en los partidos políticos, la débil organización gremial-sindical y la inexistencia de un espacio como el foro de concertación social propuesto en los acuerdos de paz constituyen factores que limitan el acceso de diferentes sectores sociales y políticos a la toma de decisiones económicas. Así, pues, sigue imperando una forma autoritaria en la toma de las decisiones económicas, las cuales son altamente influenciadas por una élite de tecnócratas.

En conclusión, la mayoría de los salvadoreños percibe que las medidas económicas anunciadas por el gobierno no se encuentran encaminadas a 
solucionar sus problemas económicos. También perciben que la lucha por la sobrevivencia diaria puede llegar a ser más difícil con estas medidas. Todo lo anterior causa preocupación y ansiedad a las mayorías populares. La inestabilidad política que pueda producirse podría justificar una reversión del proceso de transición hacia un orden democrático, en el cual la sociedad civil y el bienes- tar de las mayorías se encuentren sobre el poder militar y el bienestar de un reducido, pero poderoso grupo de salvadoreños.

San Salvador, 18 de febrero de 1995.

R. A. P. 